Supplement of Hydrol. Earth Syst. Sci., 20, 1637-1653, 2016

http://www.hydrol-earth-syst-sci.net/20/1637/2016/

doi:10.5194/hess-20-1637-2016-supplement

(C) Author(s) 2016. CC Attribution 3.0 License.

(c) (i)

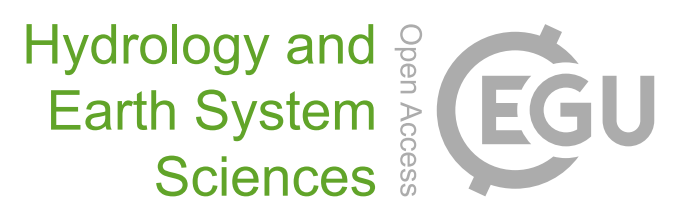

Supplement of

\title{
Assessing the quality of digital elevation models obtained from mini unmanned aerial vehicles for overland flow modelling in urban areas
}

\section{J. P. Leitão et al.}

Correspondence to: João P. Leitão (joaopaulo.leitao@eawag.ch)

The copyright of individual parts of the supplement might differ from the CC-BY 3.0 licence. 


\section{Supporting Information}

\section{A Additional plots of the impact of UAV flight parameters on DEM quality}

\subsection{Influence of flight altitude on the qualitative metrics}

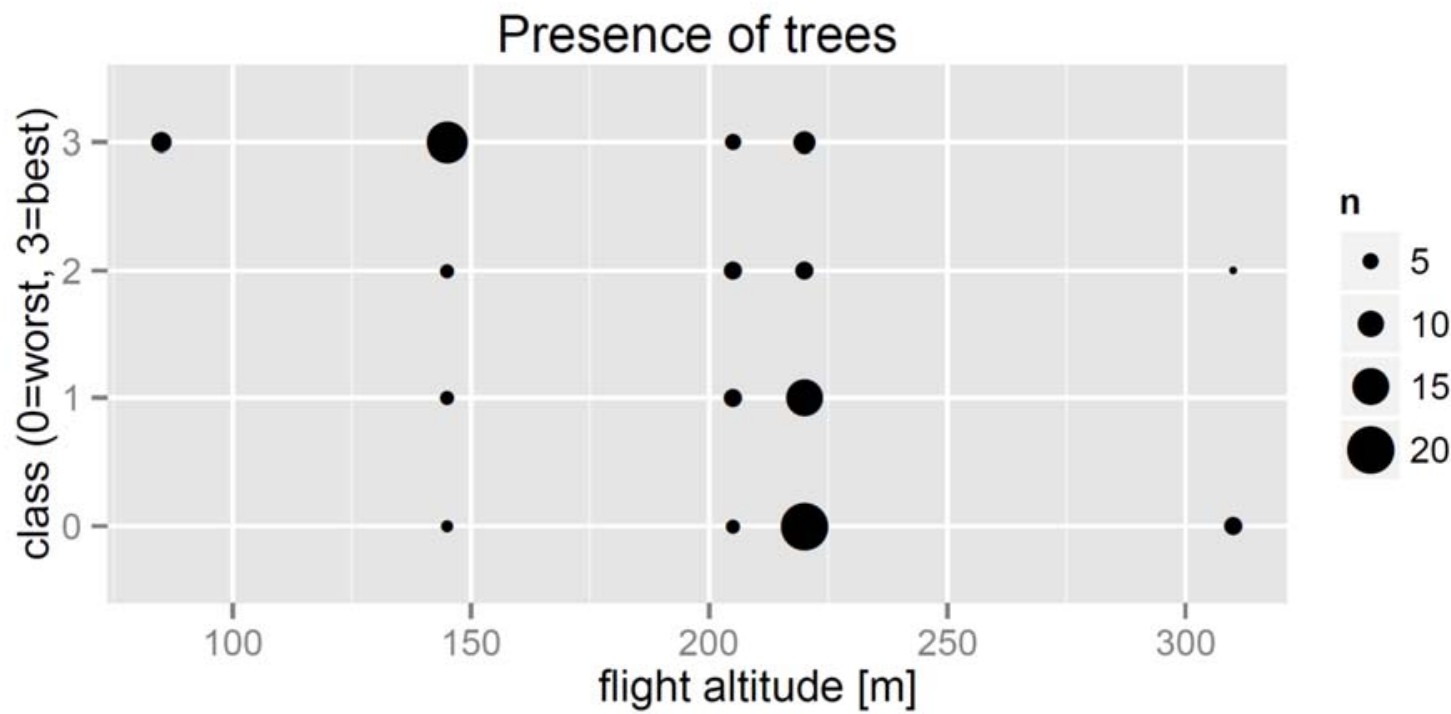

Figure 1: Relationship between the quality of the presence of trees and flight altitude. The size of the dots is proportional to the number of observed metrics with identical quality class and altitude.

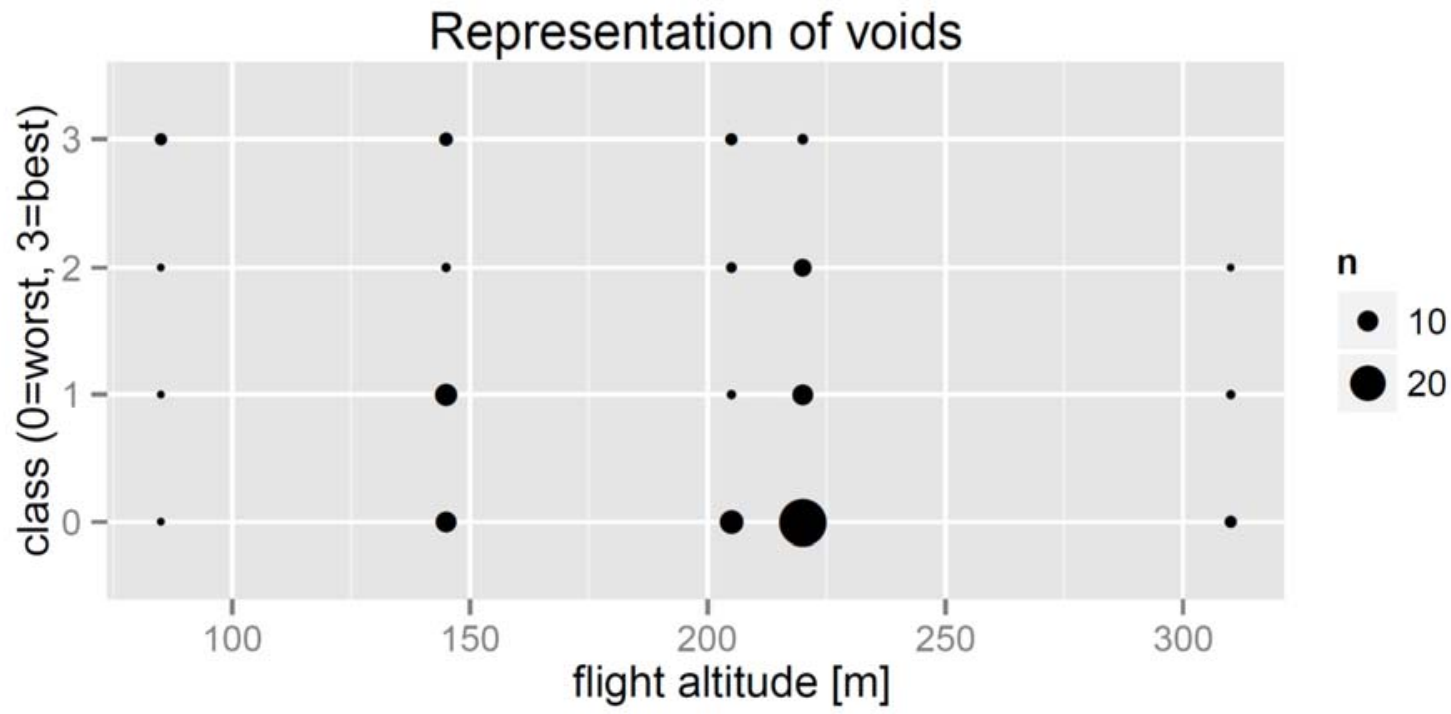


Figure 2: Relationship between the quality of the representation of voids and flight altitude. The size of the dots is proportional to the number of observed metrics with identical quality class and altitude.

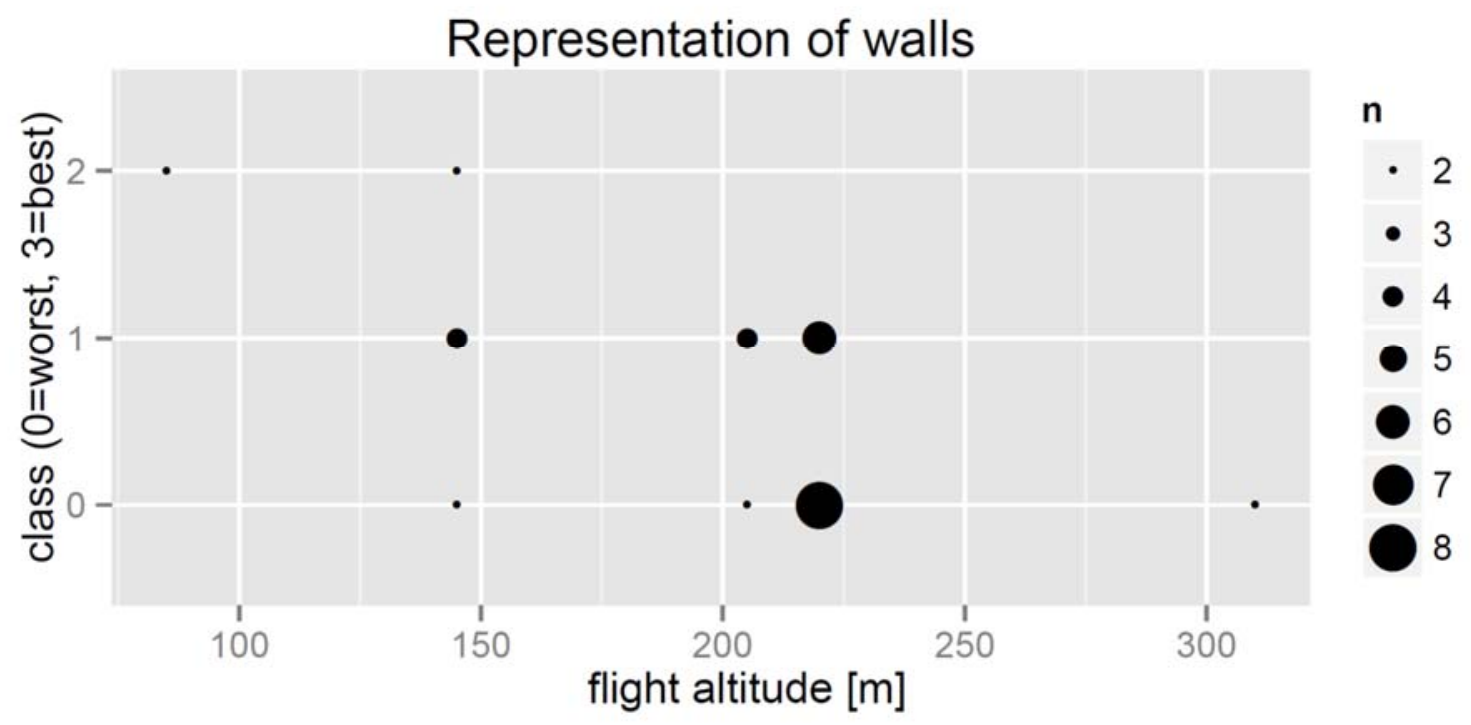

Figure 3: Relationship between the quality of the representation of walls and flight altitude. The size of the dots is proportional to the number of observed metrics with identical quality class and altitude.

\subsection{Influence of weather condition on the qualitative metrics}

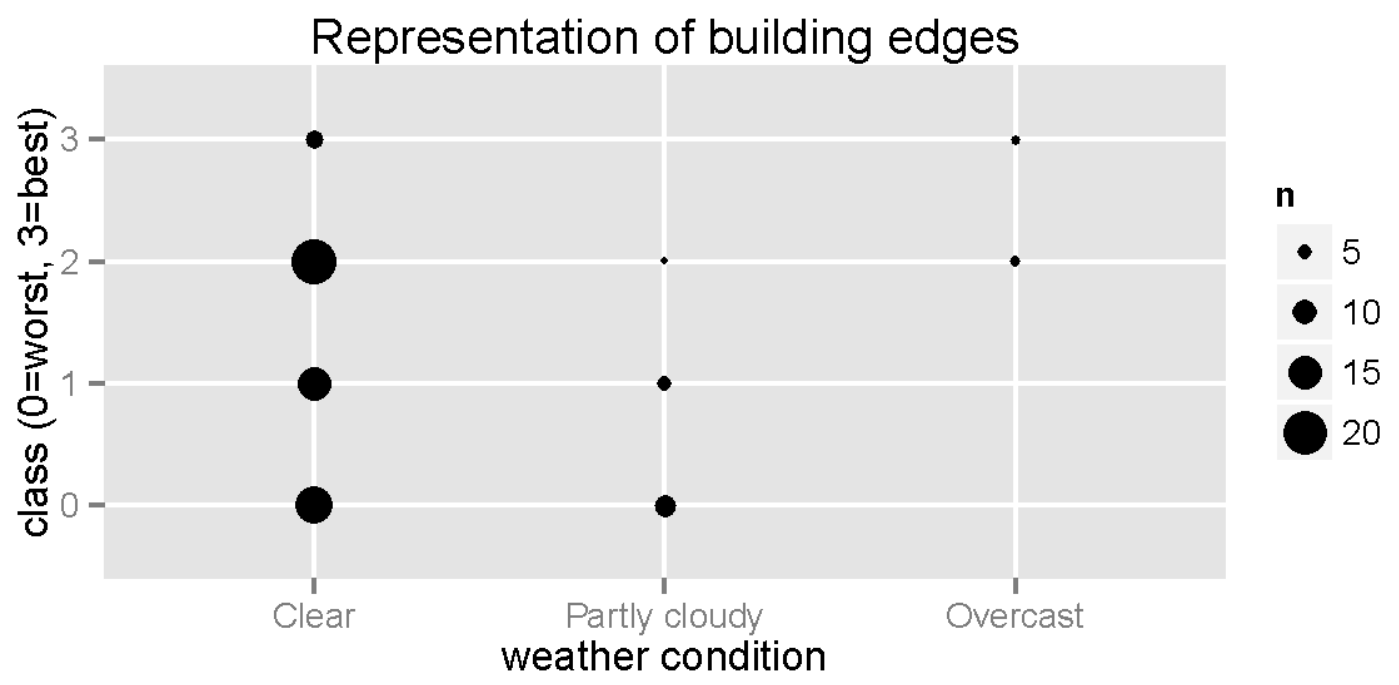


Figure 4: Relationship between the quality of the representation of building edges and weather condition. The size of the dots is proportional to the number of observed metrics with identical quality class and weather condition.

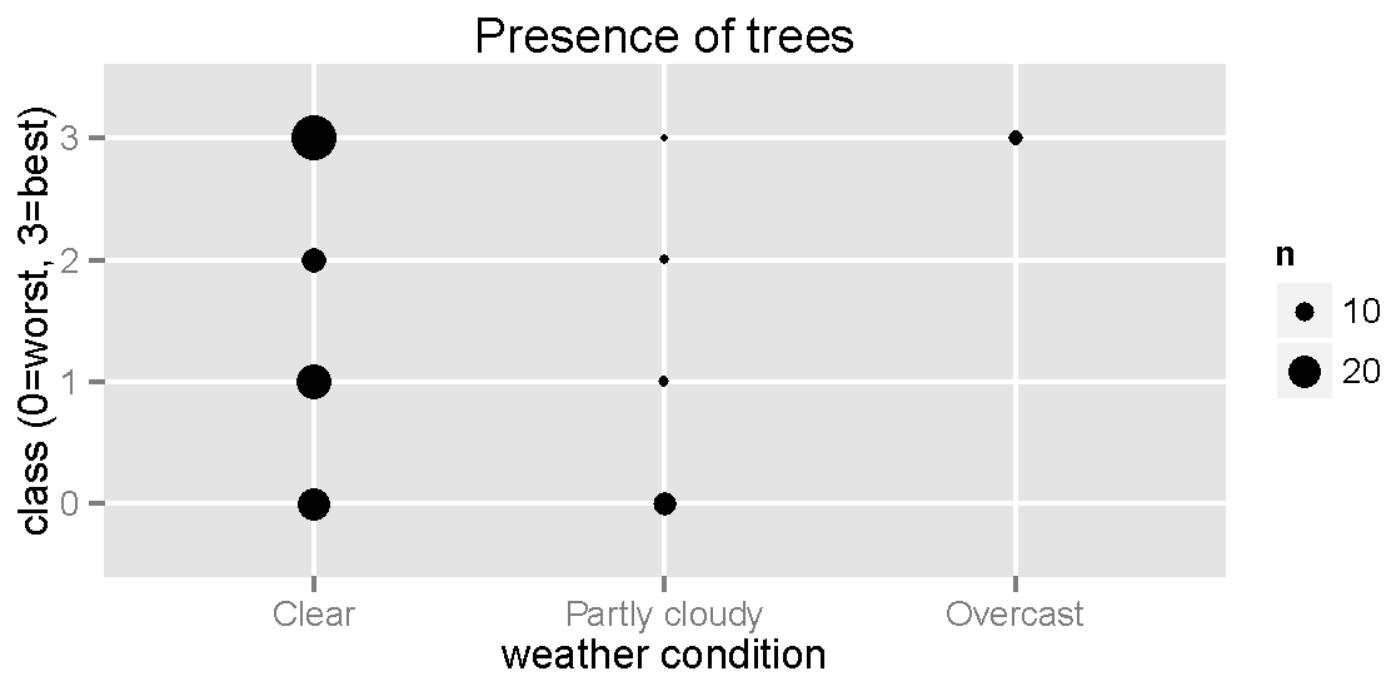

Figure 5: Relationship between the quality of the presence of trees and weather condition. The size of the dots is proportional to the number of observed metrics with identical quality class and weather condition.

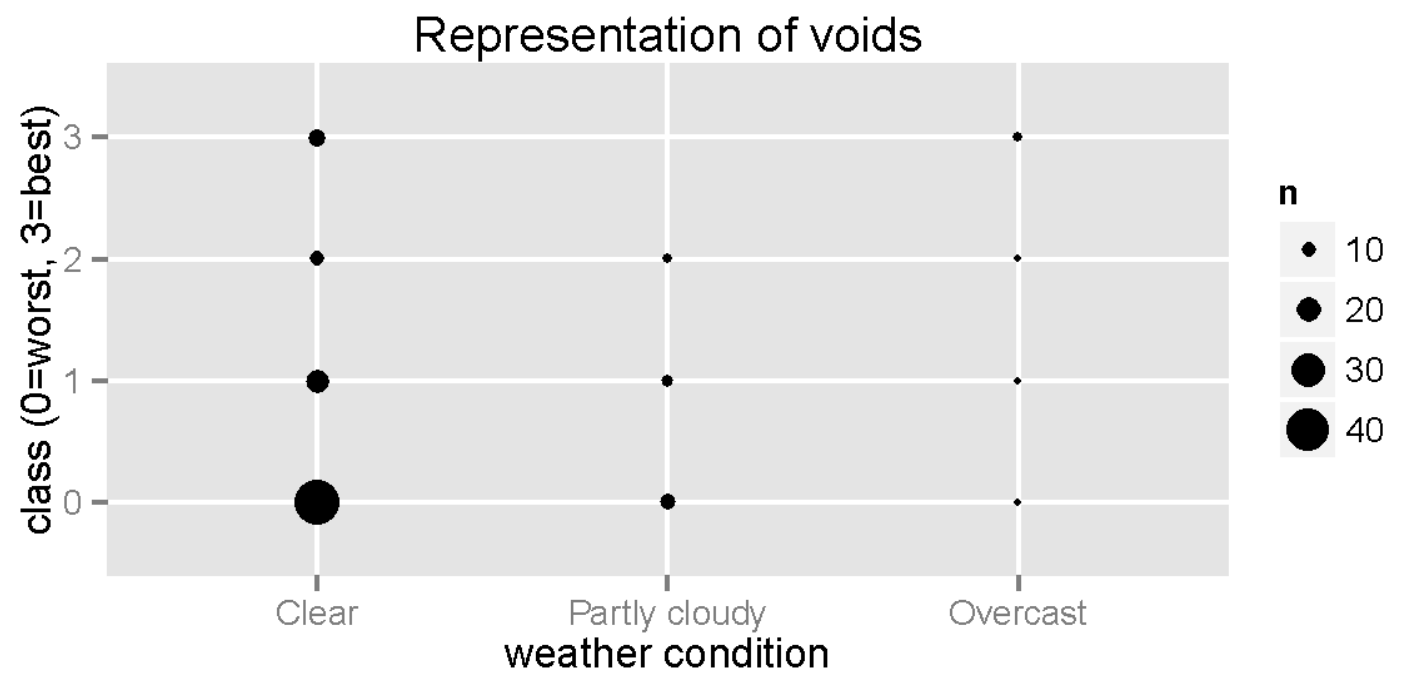

Figure 6: Relationship between the quality of the representation of voids and weather condition. The size of the dots is proportional to the number of observed metrics with identical quality class and weather condition. 


\subsection{Influence on quantitative metrics}

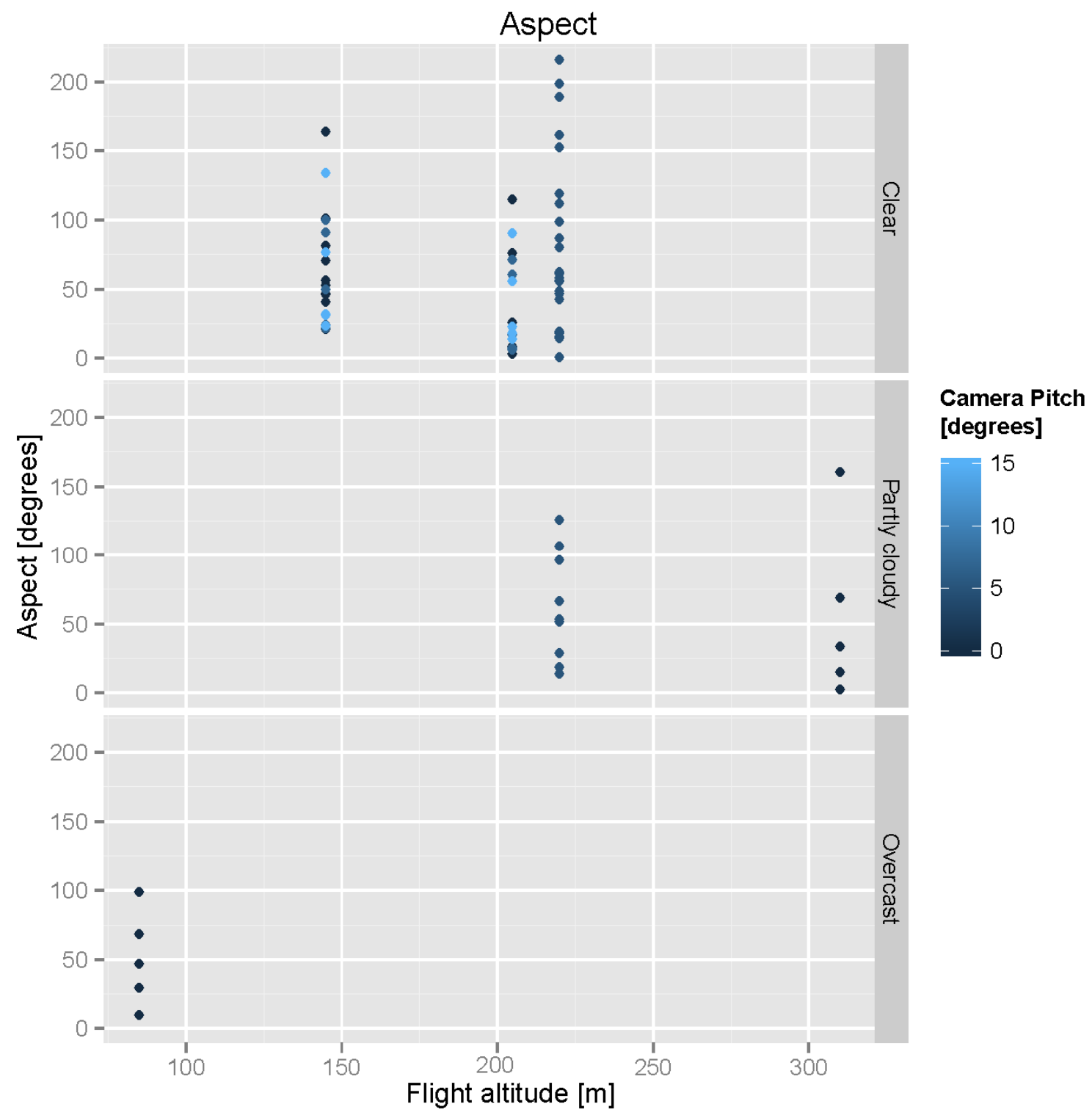

Figure 7: Relationship between the aspect deviation, flight altitude, weather condition and camera pitch. 


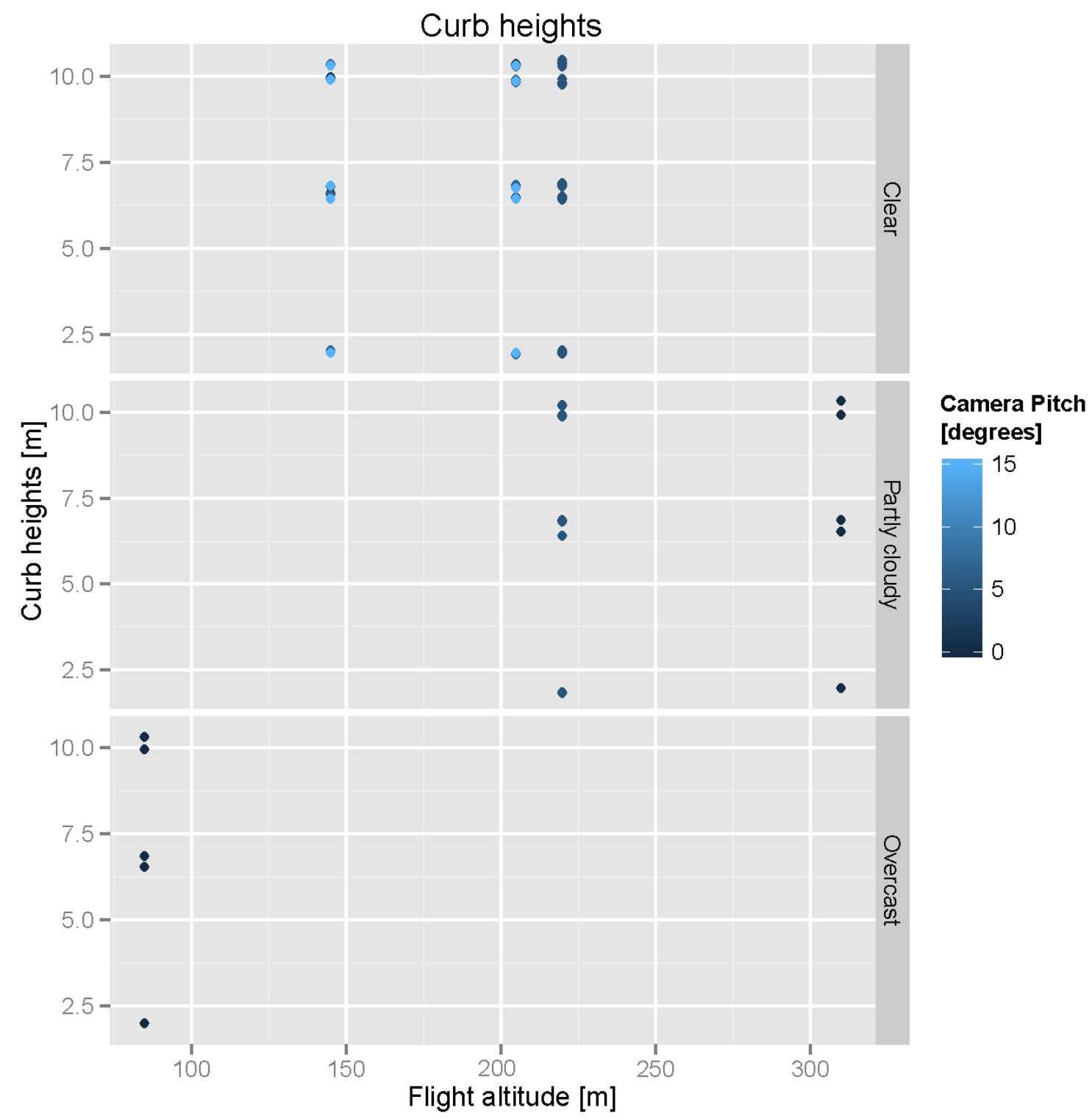

Figure 8: Relationship between the curb heights, flight altitude, weather condition and camera pitch. 


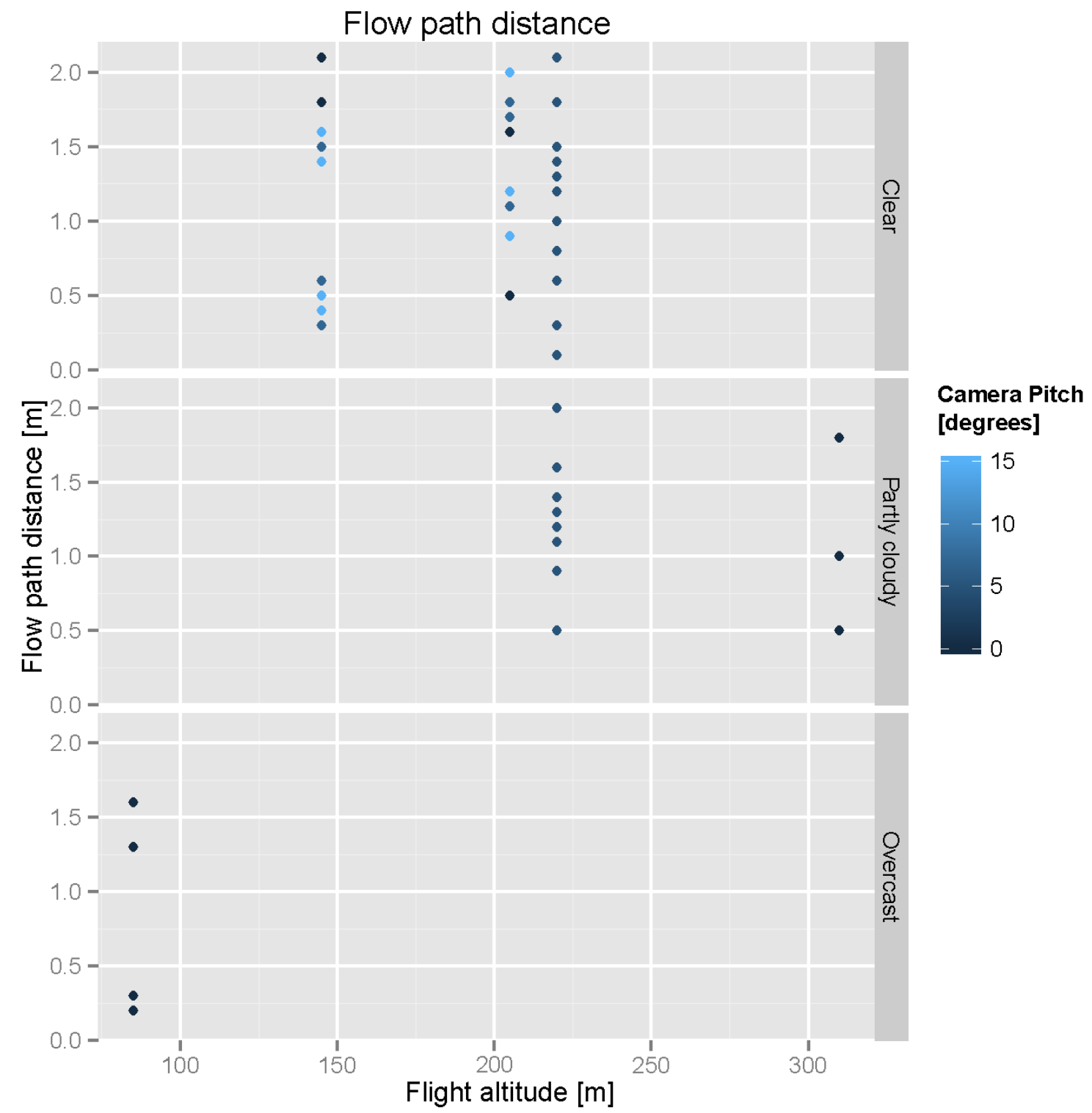

Figure 9: Relationship between the flow path distances, flight altitude, weather condition and camera pitch. 


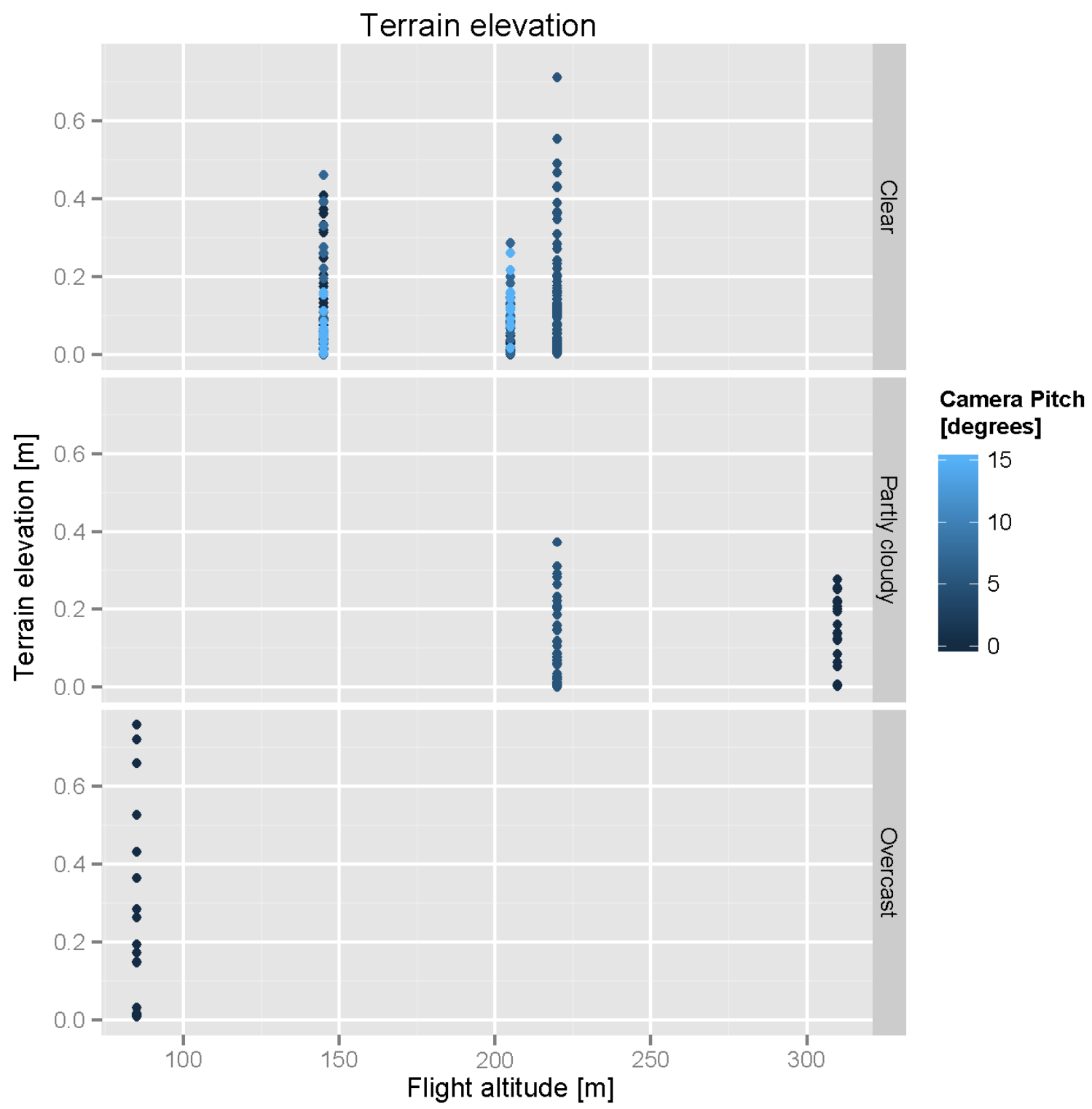

Figure 10: Relationship between terrain elevation, flight altitude, weather condition and camera pitch. 